\title{
Acute fluoxetine treatment increases aggressiveness in juvenile matrinxã (Brycon amazonicus)
}

\author{
Carla Patricia Bejo Wolkers • Mônica Serra • \\ Augusto Barbosa Júnior • \\ Elisabeth Criscuolo Urbinati
}

Received: 3 August 2016 / Accepted: 11 December 2016/Published online: 24 December 2016

(C) Springer Science+Business Media Dordrecht 2016

\begin{abstract}
Fluoxetine (FLX) is a selective serotonin (5HT) reuptake inhibitor known for its effects modifying aggressiveness, personality traits, and anxiety-like behaviors. The aim of the present study was to evaluate the influence of the acute treatment, by immersion, with FLX on aggressive behavior of resident Brycon amazonicus fish. Fish pretreated with FLX presented an increase in aggressiveness, evidenced by the increase on the number of bites and chases against the intruder and a decrease in latency for the first attack, when compared to control fish. Together with previous studies, these results show the complexity of the neural modulation of the aggressive behavior in fish by 5 -HTergic system.
\end{abstract}

Keywords Aggressive behavior Fish · Fluoxetine . Serotonin

C. P. B. Wolkers $(\bowtie) \cdot$ M. Serra • E. C. Urbinati Departamento de Morfologia e Fisiologia Animal, Faculdade de Ciências agrárias e Veterinárias/Centro de Aquicultura (CAUNESP), Universidade Estadual Paulista, UNESP, Jaboticabal, SP, Brazil

e-mail: carlawolkers@yahoo.com.br

C. P. B. Wolkers

Faculdade de Ciências Integradas do Pontal (FACIP), Universidade Federal de Uberlândia, UFU, Ituiutaba, MG, Brazil

A. Barbosa Júnior

Departamento de Ciência e Tecnologia, Secretaria de Ciência, Tecnologia e Insumos Estratégicos do Ministério da Saúde (DECIT/SCTIE/MS), Brasilia, DF, Brazil

\section{Introduction}

Numerous pharmacological, neuroanatomical, and clinical studies have suggested that serotonin (5-hydroxytryptamine or 5-HT) plays a critical role in modulating some dimensions of personality and behavior and may contribute to the symptoms observed in a wide range of related psychiatric disorders. Thus, there is substantial evidence implicating the serotonergic (5-HTergic) system as a mediator of emotional responses in animals and humans (for a review, see Gillette 2006). 5-HT primarily plays an inhibitory role in the expression of aggression and has been shown to influence the dynamics of agonistic interactions (Nelson and Chiavegatto 2001).

The evidence that the 5-HTergic system is an important modulator of mood and emotions and controls many other kinds of behaviors and physiological functions comes from pharmacological manipulation studies. The two most common methods to investigate the role of 5-HT on the modulation of aggression are the employment of selective 5-HT reuptake inhibitors (SSRIs), such as fluoxetine, paroxetine, and sertraline, and dietary supplementation with the amino acid precursor of 5-HT L-tryptophan (TRP). TRP supplemented diets have been linked to decreased aggression in several fish species (Winberg et al. 2001; Hseu et al. 2003; Lepage et al. 2005; Höglund et al. 2005; Wolkers et al. 2012, 2014). Recent studies from our laboratory using South American freshwater fish matrinxã (Brycon amazonicus, Spix and Agassiz) as a model organism demonstrated that dietary TRP supplementation for 7 days inhibited aggressiveness against a same-sized intruder, without significant alterations in hypothalamic 
5-HT levels (Wolkers et al. 2012, 2014). However, there are contradictory findings concerning the effects of SSRIs in the modulation of aggression. Both acute and chronic fluoxetine administration decrease aggressive behavior in bluehead wrasse (Thalassoma bifasciatum, Bloch) males (Perreault et al. 2003). Conversely, acute but not chronic treatment with fluoxetine increases aggression in Betta splendens (Clotfelter et al. 2007) and toadfish (Opsanus beta; McDonald et al. 2011).

Matrinxã (B. amazonicus) is an appropriate model organism to study aggression, as they display extreme aggressive behavior against intruders (Wolkers et al. 2012, 2014). Based on previous studies from our group that demonstrated decreased aggression in fish fed with the 5-HT precursor L-TRP (Wolkers et al. 2012, 2014), we hypothesize that treatment with fluoxetine, an SSRI, could also decrease the aggressive behavior of this species using the same resident-intruder paradigm. Thus, the aim of the present report was to evaluate the effect of acute treatment with fluoxetine on aggression in matrinxã.

\section{Materials and methods}

\section{Experimental treatments}

To evaluate the influence of the 5-HTergic system on aggressive behavior in B. amazonicus, we used the administration of fluoxetine, a selective serotonin reuptake inhibitor. The aggressiveness of the resident fish against the intruder after being treated with either water (Control group) or fluoxetine (FLX) during a 20-min fight was tested.

For FLX treatment, a noninvasive method was used with the addition of the drug into the water of the aquarium in order to avoid stress induced by manipulation. For this purpose, a stock solution was prepared containing $20 \mu \mathrm{g} \mathrm{mL}^{-1}$ of FLX. Twelve hours before the social challenge, $25 \mathrm{~mL}$ of this solution were added per liter of aquarium water, resulting in a final nominal concentration of FLX of $0.5 \mathrm{mg} \mathrm{L}^{-1}$.

Experimental protocol

Before the experiments, a total of 28 fish were collected from the tanks, anesthetized (benzocaine, $100 \mathrm{mg} \mathrm{L}^{-1}$, Synth, Diadema, Brazil, www.labsynth. com.br), weighed and measured, and then randomly separated into two groups (residents and intruders). For identification during interactions, animals were also tagged with a small cut on the superior (resident) or inferior (intruder) lobe of the caudal fin. The resident fish were randomly separated in two treatments, control $(n=7)$ and $\operatorname{FLX}(n=7)$, and they were kept on individual aquaria for 9 days of acclimation. Intruder fish were kept in individual tanks for the same period with the same water as the control group. On day 9, $12 \mathrm{~h}$ prior to the test, an FLX solution or vehicle was included in the resident fish aquaria. On day 10, one intruder fish was introduced into the aquarium of each resident to establish a resident/intruder relationship. Residents and intruders were similar in mass and total length (differences of less than 10\%). The behavioral interactions were recorded for $20 \mathrm{~min}$ immediately after the entrance of the intruder fish. The resident fish were anesthetized, and blood was collected by caudal vein puncture for subsequent biochemical analyses immediately after the end of the experiment. All samplings were performed between 8:00 and 11:00 a.m.

\section{Behavioral and biochemical analysis}

The agonistic behavioral patterns of the resident fish were analyzed by observing the occurrence of biting (characterized by a bite on the other fish, on any part of the body) and chasing (characterized by an explosion of locomotor activity in which one fish pursued the other without body contact) (adapted from Wolkers et al. 2012). The latency before the first attack was also analyzed. The serum cortisol levels were evaluated by radioimmunoassay (DPC kit, Diagnostic Products Corporation).

\section{Statistical analysis}

The data presented a normal distribution (KolmogorovSmirnov test, $P>0.05$ ) and homogeneity of variance (Levene's test, $P>0.05$ ) and are expressed as mean \pm standard error (S.E.). $T$ test was performed to determine the effects of the FLX treatment on the latency to the first attack, number of bites and chases, and on the cortisol levels. Only the data of resident fish were considered. 


\section{Results}

Fish treated with FLX performed more bites $(t=-3.432$, $P=0.005)$ and chases $(t=-2.578, P=0.024)$ than control (Fig. 1). Additionally, FLX-treated animals had a smaller latency to the first attack than control group $(t=2.504, P=0.028)$ (Fig. 2). The serum cortisol was not affected by the treatment $(t=1.637, P=0.124)$ (Fig. 3).

\section{Discussion}

The present report demonstrates that $12 \mathrm{~h}$ of immersion in FLX solution, an acute treatment, promoted a significant increase in aggressiveness of juvenile matrinxã compared to the control group. This result was contradictory to our hypothesis, which was based on several studies showing an inhibition of aggression after FLX treatment (Perreault et al. 2003; Lynn et al. 2007; Kania et al. 2012; Forsatkar et al. 2013). Furthermore, cortisol levels after $20 \mathrm{~min}$ of fighting with a same-sized conspecific intruder were consistent with the literature (Wolkers et al. 2014; Serra et al. 2016), with no significant difference between the treatments.

Fighting is stressful for fish (Øverli et al. 1999, 2004), and even after 12 h of FLX treatment, matrinxãs were able to properly respond to this stressor, reaching cortisol levels that were similar to the control group and consistent with cortisol levels observed in matrinxã (control fish) after a similar fight paradigm demonstrated in previous studies (Wolkers et al. 2014; Serra et al.

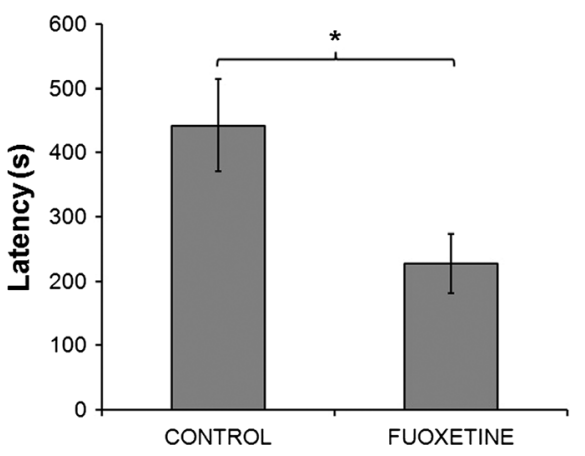

Fig. 2 Latency (seconds) to the first attack of resident B. amazonicus. Control represents fish treated with water. FLX represents fish treated with fluoxetine $\left(0.5 \mathrm{mg} \mathrm{L}^{-1}\right)$

2016). In jundiá Rhamdia quelen juveniles, a short (17 min) exposure to FLX in the water also altered the behavior (had an anxiolytic effect) without impairing the stress response (Abreu et al. 2016). Our study also demonstrated that cortisol levels were unaffected by the treatment with FLX, with both groups presenting similar hormonal levels to those described in a previous study that used FLX intraperitoneal implants for an acute treatment (McDonald et al. 2011).

The acute effect of SSRIs consists of the inhibition of the 5-HT transporter (SERT) that removes the 5-HT from the synaptic cleft back into the presynaptic neuron, leading to a consequent longer availability of synaptic 5HT (Beasley et al. 1992). This increase in the 5-HT availability promoted by the FLX treatment has been related to decreased aggressiveness in fish. In coral reef (T. bifasciatum) and betta fish (B. splendens), chronic and acute FLX treatments were effective in reducing aggressiveness (Perreault et al. 2003; Lynn et al. 2007;

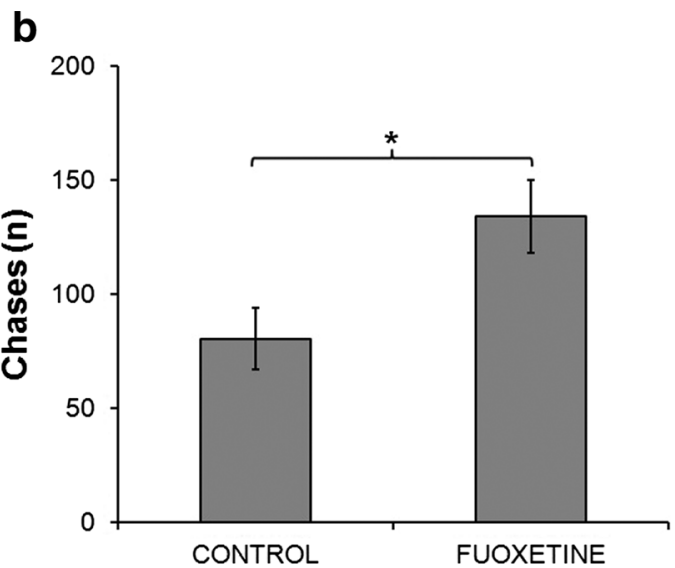

Fig. 1 Aggressive behavior of resident B. amazonicus. a Number of bites. b Number of chases. Control represents fish treated with water. $F L X$ represents fish treated with fluoxetine $\left(0.5 \mathrm{mg} \mathrm{L}^{-1}\right)$ 


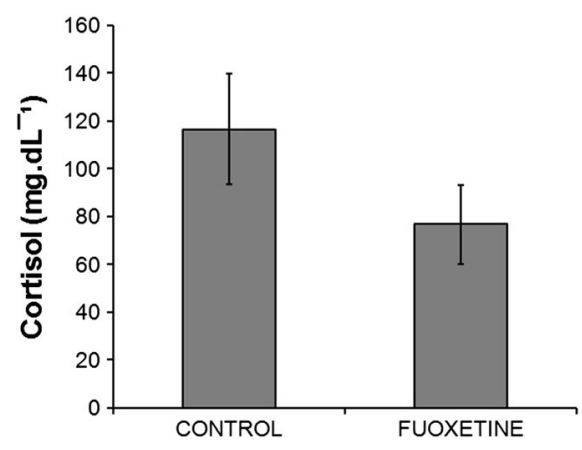

Fig. 3 Serum cortisol (mg.dL $\left.{ }^{-1}\right)$ of resident B. amazonicus. Control represents fish treated with water. $F L X$ represents fish treated with fluoxetine $\left(0.5 \mathrm{mg} \mathrm{L}^{-1}\right)$

Kania et al. 2012; Forsatkar et al. 2013). However, the decrease of aggression in fish treated with FLX is not universal. Clotfelter et al. (2007) demonstrated that chronic intraperitoneal FLX (14 days) treatment did not decrease the aggression against a mirror image, and promoted a decrease in 5-HT and 5-hydroxyindoleacetic acid (5-HIAA, the 5-HT metabolite) concentrations. Similarly to what was observed in the present study, the acute treatment with intraperitoneal FLX implants enhanced aggressiveness in dominant toadfish (Opsanus beta), even with increased circulating levels of 5-HT (McDonald et al. 2011).

Although it is difficult to compare the dosage between the studies, considering the differences in drug administration pathways, the increase in aggressiveness seems to be related with acute FLX treatments, even with increased levels of plasmatic 5-HT, as observed by McDonald et al. (2011), suggesting that the increase in 5-HT levels is not per se an inhibitor of aggression and that other mechanisms may be involved in the modulation of the aggressiveness. Furthermore, the increase in 5-HT plasmatic levels described by McDonald et al. (2012) does not exclude the possibility of a decrease in this neurotransmitter within specific brain regions through negative feedback by 5-HTergic autoreceptors (5-HT $\mathrm{H}_{1 \mathrm{~A}}$ and $\left.5-\mathrm{HT}_{1 \mathrm{~B}}\right)$, which could influence behavior. However, since the 5-HT levels were not evaluated in the present study, it is not possible to confirm this hypothesis.

Another hypothesis for the increased aggressiveness observed is the influence of FLX on anxiety and boldness. FLX is a drug with anxiolytic effects that have been reported in fish (Lynn et al. 2007; Maximino et al. 2011; Barbosa Júnior et al. 2012; Abreu et al. 2016), and lines selected for low anxiety-related behavior are more aggressive than lines with high anxiety-related behavior or nonselected mice (Neumann et al. 2010). Furthermore, FLX treatment can also improve the boldness in fish (Winberg and Thörnqvist 2016), and this effect can be related to increased aggressiveness, as proactive animals tend to be more bold and aggressive (Benus et al. 1991). Additionally, bold fish are even more likely to become dominant (Dahlbom et al. 2011). However, the methodological approach used here is not adequate to evaluate the effects of FLX on these personality traits and their relationship with aggressiveness.

\section{Conclusion}

The present study concludes that modulation of the 5HTergic system through the acute treatment with FLX increased aggressiveness in matrinxã juveniles. Further studies should be made to investigate which mechanisms drive this increase in aggressive behavior in the species after an acute modulation of the 5-HTergic system with FLX.

\section{References}

Abreu MS, Giacomini ACVV, Koakoski G, Piato AL, Barcellos LJG (2016) Evaluating anxiety-like and social behavior in jundiá (Rhamdia quelen). Physiol Behav 160:59-65. doi:10.1016/j.physbeh.2016.04.003

Barbosa Júnior A, Alves FL, Fim Pereira AS, Ide LM, Hoffmann A (2012) Behavioral characterization of the alarm reaction and anxiolytic-like effect of acute treatment with fluoxetine in piauçu fish. Physiol Behav 105(3):784-790. doi:10.1016/j. physbeh.2011.10.007

Beasley CM, Masica DN, Potvin JH (1992) Fluoxetine: a review of receptor and functional effects and their clinical implications. Psychopharmacol 107:1-10

Benus RF, Bohus B, Koolhaas JM, Vanoortmerssen GA (1991) Heritable variation for aggression as a reflection of individual coping strategies. Experientia 47:1008-1019. doi:10.1007 /BF01923336

Clotfelter ED, O'Hare EP, McNitt MM, Carpenter RE, Summers CH (2007) Serotonin decreases aggression via $5-\mathrm{HT}_{1 \mathrm{~A}}$ receptors in the fighting fish Betta splendens. Pharmacol Biochem Behav 87: 222-231. doi:10.1016/j.pbb.2007.04.018

Dahlbom SJ, Lagman D, Lundstedt-Enkel K, Sundström LF, Winberg S (2011) Boldness predicts social status in zebrafish Danio rerio. PLoS One 6(8):e23565-e23567. doi:10.1371/journal. pone. 0023565

Forsatkar MN, Abedi M, Nematollahi MA, Rahbari E (2013) Effect of testosterone and fluoxetine on aggressive behavior of fighting fish, Betta splendens. Int J Aquatic Biol 1(6):289-293 
Gillette R (2006) Evolution and function in serotonergic systems. Int Comp Biol 46:838-846

Höglund E, Bakke MJ, Øverli Ø, Winberg S, Nilsson GE (2005) Suppression of aggressive behavior in juvenile Atlantic cod (Gadus morhua) by L-tryptophan supplementation. Aquacult 249:525-531. doi:10.1016/j.aquaculture.2005.04.028

Hseu JR, Lu FI, Su HM, Wang LS, Tsai CL, Hwang PP (2003) Effect of exogenous tryptophan on cannibalism, survival and growth in juvenile grouper, Epinephelus coioides. Aquacult 218:251-263. doi:10.1016/S0044-8486(02)00503-3

Kania BF, Gralak MJ, Wielgozs M (2012) Four-week fluoxetine (SSRI) exposure diminishes aggressive behavior of male siamese fighting fish (Betta splendens). J Behav Brain Sci 2(2):185-190. doi:10.4236/jbbs.2012.22022

Lepage O, Larson ET, Mayer I, Winberg S (2005) Serotonin, but not melatonin, plays a role in shaping dominant-subordinate relationships and aggression in rainbow trout. Horm Behav 48(2):233-242. doi:10.1016/j.yhbeh.2005.02.012

Lynn SE, Egar JM, Walker BG, Sperry TS, Ramenofsky M (2007) Fish on Prozac: a simple, noninvasive physiology laboratory investigating the mechanisms of aggressive behavior in Betta splendens. Adv Physiol Educat 31(4): 358-363. doi:10.1152/advan.00024.2007

Maximino C, Silva AWB, Gouveia A Jr, Herculano AM (2011) Pharmacological analysis of zebrafish (Danio rerio) scototaxis. Progg Neuro-psycopharmacol Biol Psych 35(2): 624-631. doi:10.1016/j.pnpbp.2011.01.006

McDonald MD, Gonzalez A, Sloman KA (2011) Higher levels of aggression are observed in socially dominant toadfish treated with selective serotonin reuptake inhibitor, fluoxetine. Comp Biochem Physio C Toxicol Pharmacol 153(1):107-112. doi:10.1016/j.cbpc.2010.09.006

Nelson RJ, Chiavegatto S (2001) Molecular basis of aggression. Trends Neurosci 24:713-719. doi:10.1016/S0166-2236(00 )01996-2
Neumann ID, Veenema AH, Beiderbeck DI (2010) Aggression and anxiety: social context and neurobiological links. Front Behav Neurosci 4:1-12. doi:10.3389/fnbeh.2010.00012

Øverli Ø, Harris C, Winberg S (1999) Short-term effects of fights for social dominance and the establishment of dominantsubordinate relationships of brain monoamines and cortisol in rainbow trout. Brain Behav Evol 54:263-275. doi:10.1159 $/ 000006627$

Øverli Ø, Korzan WJ, Larson ET, Winberg S, Lepage O, Pottinger TG (2004) Behavioral and neuroendocrine correlates of displaced aggression in trout. Horm Behav 45(5):324-329. doi: $10.1159 / 000006627$

Perreault HAN, Semsar K, Godwin J (2003) Fluoxetine treatment decreases territorial aggression in a coral reef fish. Physiol Behav 79:719-724. doi:10.1016/S0031-9384(03)00211-7

Serra M, Wolkers CPB, Mello, MMM, Urbinati EC (2016). Agonistic trials with mirrors do not elicit the same aggressiveness of a real trial in the matrinxã fish, Brycon amazonicus (Spix \& Agassiz, 1929). doi:10.1111/jai.13198

Winberg S, Thörnqvist PO (2016) Role of brain serotonin in modulating fish behavior. Curr Zool 62:1-7. doi:10.1093/cz/zow037

Winberg S, Overli O, Lepage O (2001) Suppression of aggression in rainbow trout (Oncorhynchus mykiss) by dietary L-tryptophan. J Exp Biol 204:3867-3876

Wolkers CPB, Serra M, Hoshiba MA, Urbinati EC (2012) Dietary L-tryptophan alters aggression in juvenile matrinxã Brycon amazonicus. Fish Physiol Biochem 38: 819-827. doi:10.1007/s10695-011-9569-X

Wolkers CPB, Serra M, Urbinati EC (2014) The time course of aggressive behavior in juvenile matrinxã Brycon amazonicus fed with dietary L-tryptophan supplementation. J Fish Biol 84(1):45-57. doi:10.1111/jfb.12252 